\title{
Timing of Coronary Angiography After Successful Fibrinolytic Therapy in ST-Segment Elevated Myocardial Infarction
}

\author{
Salih Kilic ${ }^{\mathrm{a}, \mathrm{c}}$, Cuneyt Turkoglu ${ }^{\mathrm{b}}$
}

\begin{abstract}
Background: We aimed to compare outcomes of patients received successful fibrinolytic treatment (FT) for ST-segment elevated myocardial infarction (STEMI) and performed coronary angiography (CAG) within $24-72 \mathrm{~h}$ or after $72 \mathrm{~h}$.
\end{abstract}

Methods: Between March 2013 and November 2014, 76 STEMI patients received successful FT and performed CAG $>24 \mathrm{~h}$ were included in the study. Patients were divided into two groups according to the time-interval from FT admission to CAG performing (Group-1, 24 - 72 h $(\mathrm{n}=29)$, Group-2, > $72 \mathrm{~h}(\mathrm{n}=47))$. The primary end point was major adverse cardiac events (MACE) defined as cardiovascular death, non-fatal myocardial infarction, and heart failure.

Results: The mean age of patients were $56 \pm 11.4$ years old $(27.6 \%$ female). CAG was performed within mean $2.17 \pm 0.38$ days in the Group- 1 and $2.9 \pm 11.5$ days in the Group $2(\mathrm{P}<0.001)$. At shortterm follow-up (6 months), MACE rate was higher in Group-2 $(21.3 \%)$ than Group-1(13.8\%), but it was not statistically significant $(\mathrm{P}=0.661)$. The rate of MACE was $37.9 \%$ in Group- 1 and $38.3 \%$ in Group-2 ( $\mathrm{P}=0.974)$ in the long-term follow-up (median: 57 months). Overall cardiac mortality rate was $7.9 \%$, the re-infarction rate was $19.7 \%$ and heart failure was $17.1 \%$ in long-term follow-up, and there were no significant difference between groups.

Conclusions: Present study has shown that performance of CAG after $24 \mathrm{~h}$ of successful FT, within $24-74 \mathrm{~h}$ or $>72 \mathrm{~h}$, did not shown any difference in term of MACE both in short and long-term followup.

Keywords: Fibrinolytic treatment; ST-segment elevated myocardial infarction; Coronary angiography

Manuscript submitted December 13, 2018, accepted December 26, 2018

aDepartment of Cardiology, Doctor Ersin Arslan Research and Training Horpital, Gaziantep, Turkey

${ }^{b}$ Department of Cardiology, Ege University Faculty of Medicine, Izmir, Turkey

${ }^{c}$ Corresponding Author: Salih Kilic, Department of Cardiology, Doctor Ersin Arslan Research and Training Horpital, Gaziantep, Turkey.

Email: kilicsalihhh@gmail.com

doi: https://doi.org/10.14740/cr817

\section{Introduction}

Early reperfusion in patients with ST-segment elevation myocardial infarction (STEMI) has been shown to improve clinical outcomes. Primary percutaneous coronary intervention (PCI) represents the gold standard reperfusion treatment of the occluded epicardial arteries $[1,2]$. However, fibrinolytic treatment (FT) still remains the gold standard option, where primary PCI cannot be performed in the recommended time [1-3]. Relevant guidelines for the management of STEMI published recommend to perform coronary angiography (CAG) and if necessary PCI within $24 \mathrm{~h}$ after successful FT $[1,3]$. Also, same guidelines recommend to do not perform CAG 2 or $3 \mathrm{~h}$ after successful FT. However, many patients do not perform PCI after successful FT in the recommended time interval since many different reasons. Although many previous studies determined the advantageous of early PCI strategy $(<$ $24 \mathrm{~h}$ ) after successful FT, few studies published concerning the results of exceeding $24 \mathrm{~h}$ from successful FT to CAG [4-6]. Also, long-term benefits of CAG after the recommend time interval are not clear. On this background, we aimed to compare the short and long-term outcomes of STEMI patients who received successful FT and did not perform CAG within $24 \mathrm{~h}$ and underwent CAG within $24-72 \mathrm{~h}$ or after $72 \mathrm{~h}$.

\section{Materials and Methods}

\section{Study design and definition of variables}

Between March 2013 and November 2014, all consecutive patients with the diagnosis of STEMI who were submitted to FT as primary strategy of reperfusion and did not perform CAG within $24 \mathrm{~h}$ after successful FT were included in the study. STsegment elevated myocardial infarction (STEMI) was defines as following criteria: ST-segment elevation $\geq 0.1 \mathrm{mV}$ in two or more leads $(0.2 \mathrm{~mm}$ for V1 - V3) or a new-onset left bundle branch block on an electrocardiogram, and typical ongoing ischemic chest pain for longer than $30 \mathrm{~min}$ [7]. The study was designed as prospective and observational. Patients who performed rescue PCI in the context of an unsuccessful TT (without reduction of ST-segment elevation, persistent chest pain for $90 \mathrm{~min}$ after initiation of thrombolysis or hemodynamic instability) were excluded. Moreover, patients who were $<18$ 
years old or $>85$ years old, or whose symptoms of myocardial infarction present for $>12 \mathrm{~h}$, pregnancy, standard exclusion criteria for FT, and having history of heart failure were exluded from the study [1].

All patients received standard weight-adjusted dose fibrin specific thrombolytic agent within 10 min after the first medical contact in emergency service. Also, all patients received aspirin $300 \mathrm{mg}$ orally, clopidogrel $300 \mathrm{mg}$ on the first day, and enoxaparin $30 \mathrm{mg}$ intravenously followed by a subcutaneous dose of $1 \mathrm{mg} / \mathrm{kg}$ repeated every $12 \mathrm{~h}$ up to hospital discharge or revascularization for a maximum of 7 days [3]. In addition, all patients received beta-blockers, statin and angiotensinconverting enzyme inhibitors unless contraindication. Also, all patients received clopidogrel $75 \mathrm{mg}$ daily for 12 months at the discretion of the treating physician.

Patients who were newly diagnosed with diabetes mellitus (DM) or were already on anti-diabetic therapy, or whose fasting plasma glucose $\geq 126 \mathrm{mg} / \mathrm{dL}$ were identified as diabetic [8]. Hypertension was defined as blood pressure (BP) $\geq 140 / 90 \mathrm{~mm} \mathrm{Hg}$ or the use of antihypertensive medication. Smoking was defined as smoking $\geq 1$ cigarettes a day for at least 1 year, without an attempt to quit. Dyslipidemia, defined as total cholesterol $\geq 174 \mathrm{mg} / \mathrm{dL}$ or on the treatment with lipidlowering drugs. Heart failure was diagnosed based on relevant guidelines of European Society of Cardiology [9]. Routine echocardiography was performed before discharge (Vivid-7, GE Healthcare) in the line of American Echocardiography Society guideline [10]. All routine laboratory parameters were recorded in planned control from hospital digital system. The researchers adhered to the principles of Helsinki Declaration throughout the study and the protocol of the study was approved by the Ethical Committee of Ege University, Faculty of Medicine.

For the purpose of this study, 76 consecutive patients with successful FT were included. The population was divided into two groups according to the time interval from FT admission to CAG performing; Group-1, patients who underwent CAG within 24 - 72 h after FT; Group-2, patients who underwent coronary angiography after $72 \mathrm{~h}$ of FT.

\section{Outcomes and follow-up}

The primary end point was major adverse cardiac events (MACE) defined as cardiovascular death, non-fatal myocardial infarction, and heart failure. Secondary end points were the individual component of primary end point. To assess clinical status and adverse events, patients were seen at the outpatient clinic 6 months and 1 year after index event. At 2, 3, 4 and 5 years, clinical follow-up was performed through telephone contact. All patients were followed for a median 57 months (interquartile range 48 - 69 months).

\section{Statistical analyses}

Statistical analyses were conducted using the Statistical Package for the Social Sciences (SPSS 20.0) for Windows (SPSS Inc., Chicago, Illinois, USA). Continuous data were presented as means and standard deviation. The Kolmogorov-Smirnov test was used to evaluate whether the continuous variables were normally distributed. Differences in continuous variables between the two groups were determined by Student's $t$-test or Mann-Whitney U-test. Categorical variables were summarized as percentages and were compared by the Chi-square test or Fisher's exact test. A survival analysis between the two groups was performed using the Kaplan-Meier method with a log-rank analysis. A P value $<0.05$ was considered statistically significant.

\section{Results}

Totally 76 patients were included in the study, and all patients were followed for a median 57 months (interquartile range 48 - 69 months). The baseline clinical features of patients were summarized in Table 1. The mean age of patients were $56 \pm$ 11.4 years old ( $27.6 \%$ female). There were no significant differences between groups in term of clinical characteristics and laboratory parameters except family history of coronary artery disease (Group-1: 37.9\% vs.Group-2: 12.8\%; $\mathrm{P}=0.001$ ), diabetes mellitus (Group-1: 31.0\% vs. Group-2: 8.5\%; $\mathrm{P}=0.025$ ), and left ventricular ejection fraction (Group-1: $53.4 \pm 8.7 \%$ vs. Group-2: $46.0 \pm 9.2 \%$; $\mathrm{P}=0.003$ ). Vast majority of patient received FT within $3 \mathrm{~h}$ of symptom onset (Table 2). All patients in both groups were referred to $\mathrm{CAG}$; the procedure was delayed by a mean time of $2.17 \pm 0.38$ days in the Group- 1 and $2.9 \pm 11.5$ days in the Group $2(\mathrm{P}<0.001)$. The total number of PCI procedures was similar between groups (Table 2). At discharge, $100 \%$ of patients were prescribed aspirin, $100 \%$ clopidogrel, $98.7 \%$ statins, $93.4 \%$ beta-blockers, and $89.5 \%$ angiotensin converter enzyme or angiotensin receptor blocker, with no difference between groups. At 6 months, medication was unchanged (Table 3).

The clinical outcomes at short-term (6 months) and longterm (median 57 months) follow-up were listed in Table 4. At short-term follow-up, MACE rate was higher in Group-2 than Group-1 but it was not statistically significant $(21.3 \%$ vs. $13.8 \% ; \mathrm{P}=0.661$, respectively). Also, overall cardiac mortality rate was $1.3 \%$, the re-infarction was $9.2 \%$, and heart failure was $14.5 \%$ at 6 months follow-up and similar between groups (Table 4). Overall, the rate of the MACE was $38.2 \%$ in longterm follow-up. The rate of MACE was $37.9 \%$ in Group- 1 and $38.3 \%$ in Group-2 $(\mathrm{P}=0.974)$. In addition, overall cardiac mortality rate was $7.9 \%$, the re-infarction rate was $19.7 \%$ and heart failure was $17.1 \%$ in long-term follow-up; and there were no significant difference between groups (Table 4). The MACEfree survivals across the groups are shown in Figure 1. Predicting survival with a combination of cardiovascular death, non-fatal myocardial infarction, and heart failure showed no significant difference in survival between groups.

\section{Discussion}

The present study has shown that performing CAG after successful FT within $24-72 \mathrm{~h}$ or after $72 \mathrm{~h}$ did not cause differ- 
Table 1. Baseline Characteristics of Study Population

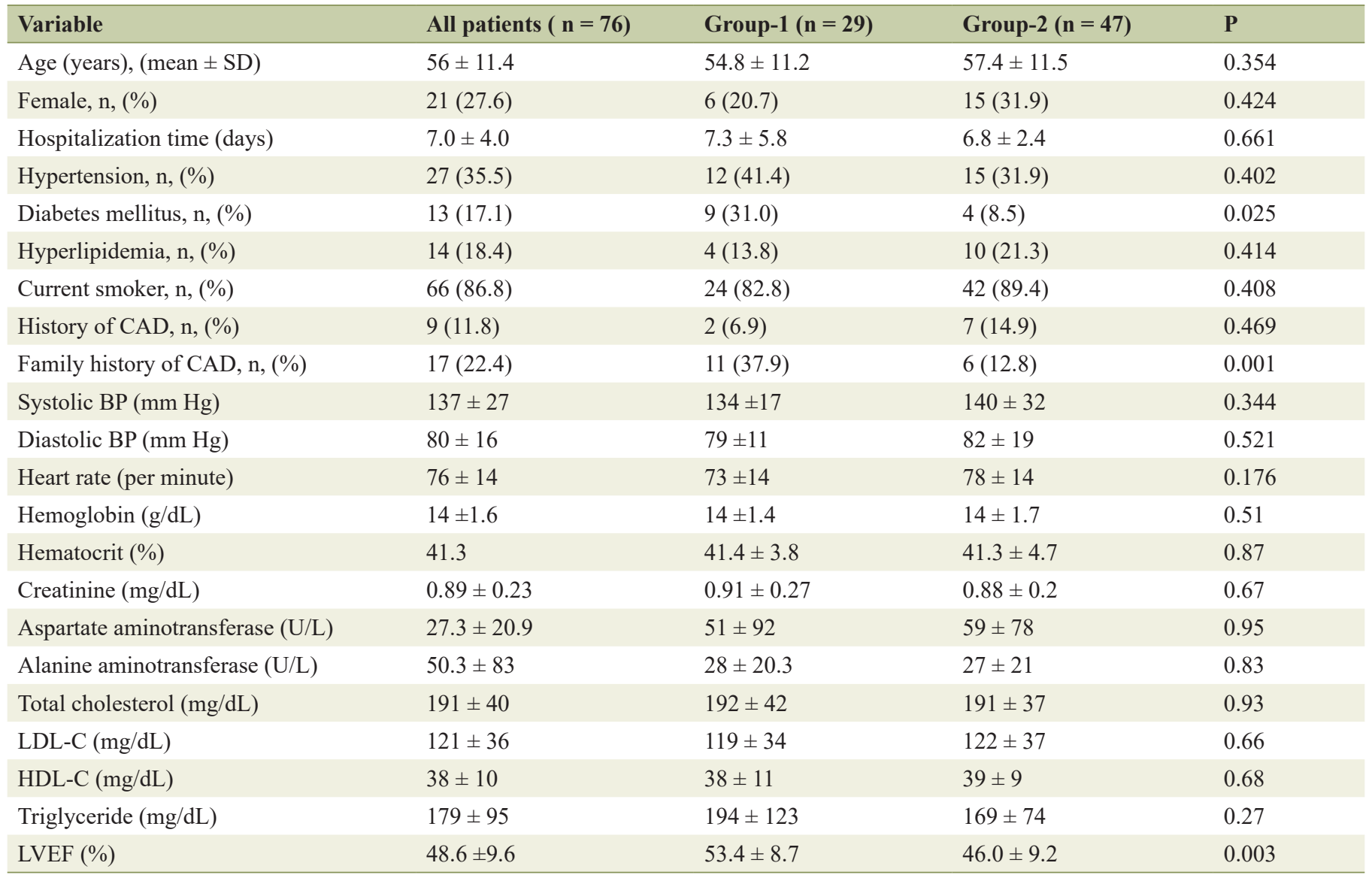

BP: blood pressure; CAD: coronary artery disease; HDL-C: high density lipoprotein cholesterol; LDLC-C: low density lipoprotein cholesterol; LVEF: left ventricular ejection fraction.

ent MACE rate both in short and long-term follow-up. Also there were no significant different between groups in term of secondary end points, cardiovascular death, re-infarction, and heart failure.

Nowadays, performance of a routine early CAG within 24 $\mathrm{h}$ is recommended after successful FT, if there are no contraindications $[1,2]$. In case of unsuccessful thrombolysis patients should undergo immediate CAG and rescue PCI $[1,2]$. Many previous studies have shown that an early routine CAG after successful FT reduced the rate of recurrent ischemia and re-infarction, compared with a watchful waiting strategy [5, 11-15]. Although these studies have variable time windows between FT and CAG, all of them were less than $24 \mathrm{~h}$. In this context, the time window from FT to CAG is $2-24 \mathrm{~h}$ in recent guideline of European Society of Cardiology and 2 or $3-24 \mathrm{~h}$ in American Heart Association guideline with a IIa level of rec-

Table 2. Procedural Characteristics

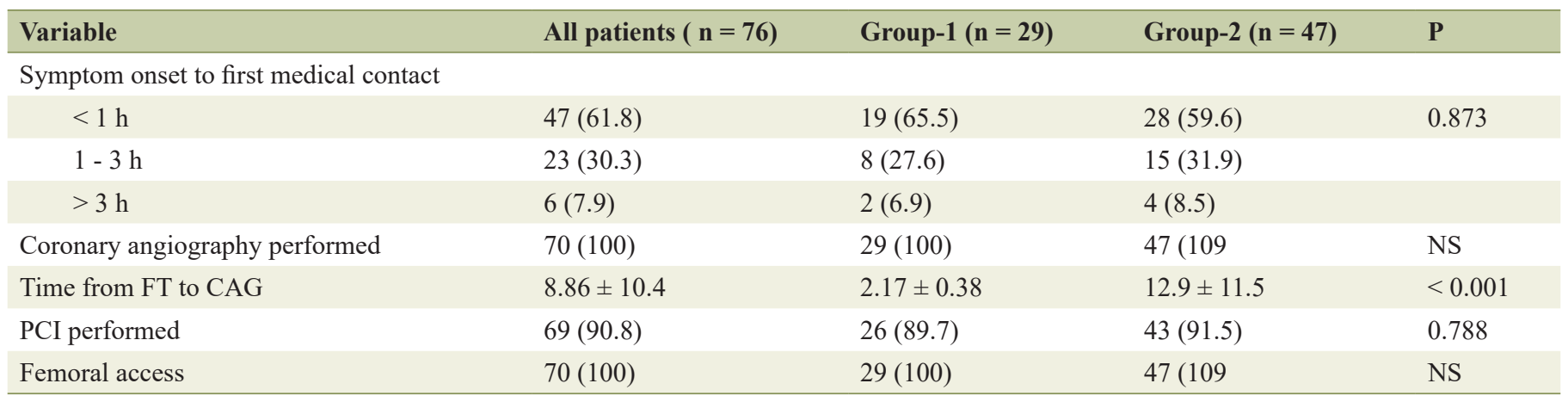

CAG: coronary angiography; FT: fibrinolytic treatment; $\mathrm{PCl}$ : percutaneous coronary intervention. 
Table 3. Medication at Discharge and 6 Months Follow-Up

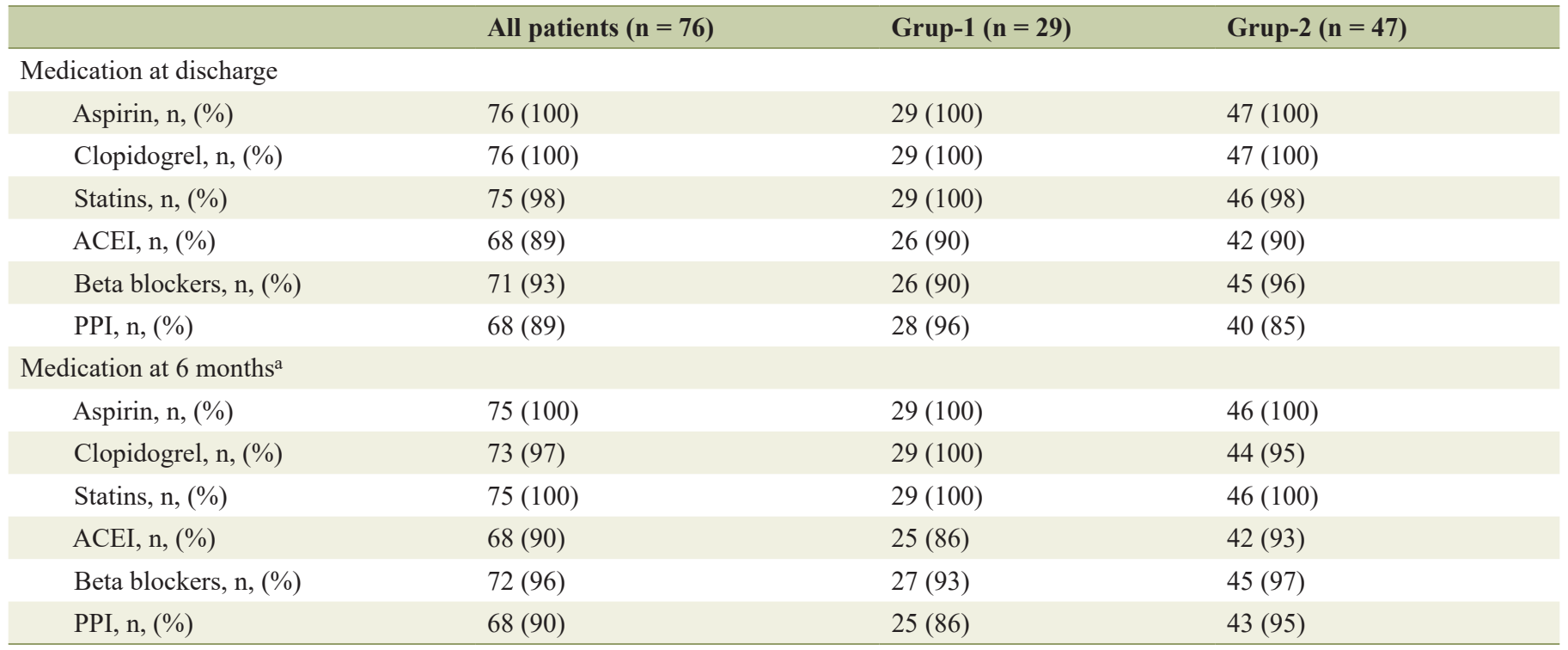

aOne patient in Group-2 died at the fourth month. ACEI: angiotensin converting enzyme inhibitor.

ommendation $[1,2]$. Despite the recommendation of relevant guidelines, previous studies have shown that a high number of patients do not perform CAG within $24 \mathrm{~h}[4,16]$. In their study Costa et al has emphasized that two-thirds of the patients performed CAG $>24 \mathrm{~h}$ after successful FT [4]. Despite catheterization laboratories that performing PCI, $24 \mathrm{~h}$ a day and 7 days a week, seem to be increasing, in the same time the number of patients that referred to these hospitals increased. With the increasing number of patients in this center the stable patients might be schedule to the following days for performing CAG. Similarly, during the weekend, most of the catheterization laboratories just perform PCI for urgent patients and stable patients are frequently scheduled to the following working days, especially Monday. Many previous studies determined the advantageous of early PCI strategy $(<24 \mathrm{~h})$ after successful FT, however there are few studies published concerning the results of exceeding $24 \mathrm{~h}$ time window from successful FT to CAG
[4]. In their study Costa et al [4] have shown that performing CAG outside of the $24 \mathrm{~h}$ time interval did not lead to higher in hospital mortality. In addition, the writing committee of American Heart Association guideline of management of STEMI believes that performing CAG beyond $24 \mathrm{~h}$ after successful FT likely will continue to benefit those patients with a patent but stenotic infarct artery. In stable patients who do not perform CAG within $24 \mathrm{~h}, \mathrm{CAG}$ can be considered as part of a routine pharmacoinvasive or ischemia-guided approach $>24 \mathrm{~h}$ after administration of FT. However, the time-interval after $>24 \mathrm{~h}$ is not clear. Moreover, to our best knowledge, there is no clinical study that evaluated the both short and long-term results of CAG performing $>24 \mathrm{~h}$ after successful FT. In this context, to clarify the time intervals and evaluated the short and long-term results of CAG after $>24 \mathrm{~h}$, we defined two time interval as early $(24-72 \mathrm{~h})$ and late $(>72 \mathrm{~h})$. We have shown that there were no significant differences between two time-intervals in

Table 4. Clinical Outcomes of Short and Long-Term Follow-Up

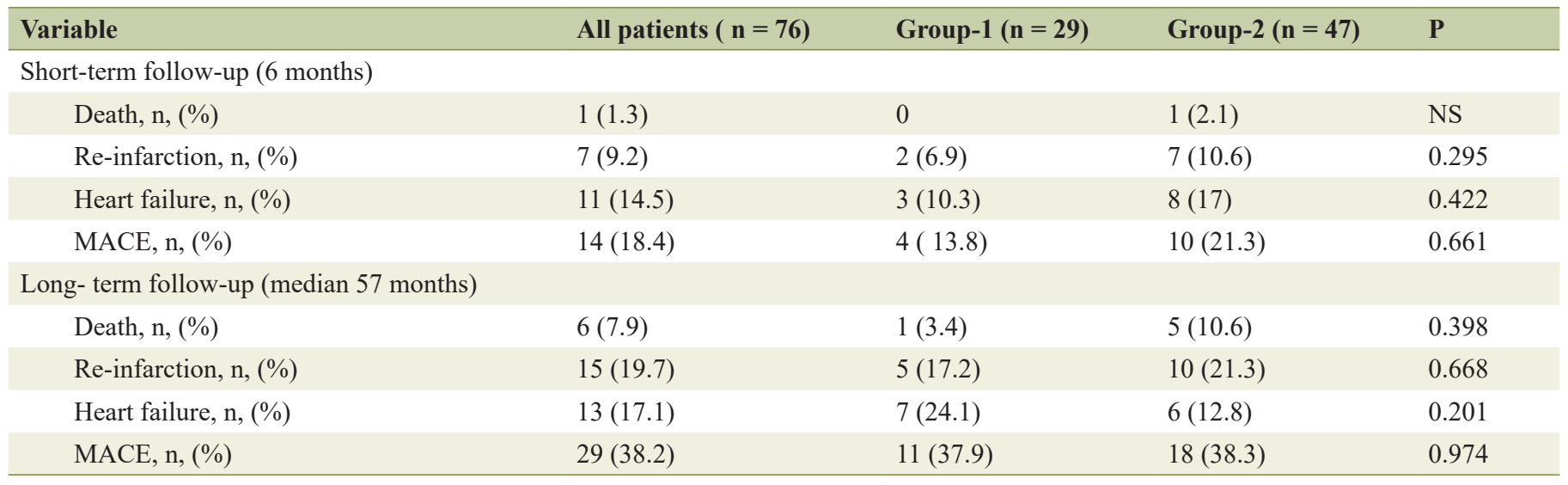

NS: non-significant; MACE: major adverse cardiac events. 


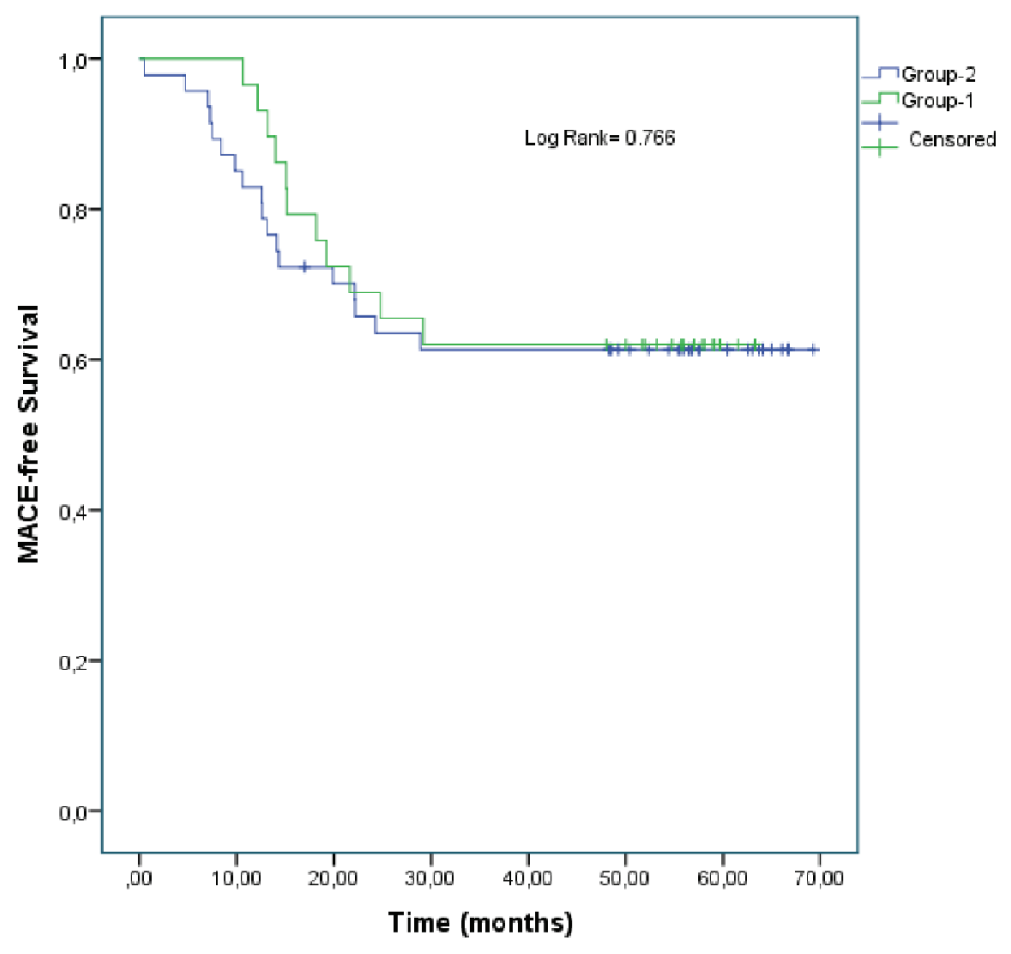

Figure 1. Kaplan-Meier analysis freedom from MACE.

term of MACE both in short and long-term follow-up. Similarly, there were no significant differences between groups in secondary end points; cardiovascular death, re-infarction, and heart failure and event-free survival.

\section{Limitations}

The presents study has several limitations that should be acknowledged: 1) It is a single center study and the number of patients are small; 2) The evaluation of the ideal time for CAG was not performed and just two groups were compared according to time interval; 3) The patients performed CAG $<24 \mathrm{~h}$ were not included the study.

\section{Conclusions}

In present study, it was shown that performance of coronary angiography in patients with STEMI after $24 \mathrm{~h}$ of successful FT, within $24-74 \mathrm{~h}$ or $>72 \mathrm{~h}$, did not show any significant difference in term of MACE both in short and long-term followup.

\section{References}

1. Ibanez B, James S, Agewall S, Antunes MJ, BucciarelliDucci C, Bueno H, Caforio ALP, et al. 2017 ESC Guidelines for the management of acute myocardial infarction in patients presenting with ST-segment elevation: The Task Force for the management of acute myocardial infarction in patients presenting with ST-segment elevation of the European Society of Cardiology (ESC). Eur Heart J. 2018;39(2):119-177.

2. Levine GN, Bates ER, Blankenship JC, Bailey SR, Bittl JA, Cercek B, Chambers CE, et al. 2015 ACC/AHA/ SCAI Focused Update on Primary Percutaneous Coronary Intervention for Patients With ST-Elevation Myocardial Infarction: An Update of the 2011 ACCF/AHA/SCAI Guideline for Percutaneous Coronary Intervention and the 2013 ACCF/AHA Guideline for the Management of ST-Elevation Myocardial Infarction. J Am Coll Cardiol. 2016;67(10):1235-1250.

3. Task Force on the management of STseamiotESoC, Steg PG, James SK, Atar D, Badano LP, Blomstrom-Lundqvist $\mathrm{C}$, Borger MA, et al. ESC Guidelines for the management of acute myocardial infarction in patients presenting with ST-segment elevation. Eur Heart J. 2012;33(20):25692619.

4. Costa C, Durao D, Belo A, Domingues K, Santos B, Leal M, Investigators of the Portuguese Registry of Acute Coronary S. Coronary angiography after successful thrombolysis - Is the recommended time interval of $24 \mathrm{~h}$ an important issue? Int J Cardiol. 2016;222:515-520.

5. D'Souza SP, Mamas MA, Fraser DG, Fath-Ordoubadi F. Routine early coronary angioplasty versus ischaemiaguided angioplasty after thrombolysis in acute ST-elevation myocardial infarction: a meta-analysis. Eur Heart J. 2011;32(8):972-982. 
6. Madan M, Halvorsen S, Di Mario C, Tan M, Westerhout CM, Cantor WJ, Le May MR, et al. Relationship between time to invasive assessment and clinical outcomes of patients undergoing an early invasive strategy after fibrinolysis for ST-segment elevation myocardial infarction: a patient-level analysis of the randomized early routine invasive clinical trials. JACC Cardiovasc Interv. 2015;8(1 Pt B):166-174.

7. Thygesen K, Alpert JS, Jaffe AS, Simoons ML, Chaitman BR, White HD, Joint ESCAAHAWHFTFfUDoMI, et al. Third universal definition of myocardial infarction. J Am Coll Cardiol. 2012;60(16):1581-1598.

8. European Guidelines on cardiovascular disease prevention in clinical practice (version 2012) The Fifth Joint Task Force of the European Society of Cardiology and Other Societies on Cardiovascular Disease Prevention in Clinical Practice (constituted by representatives of nine societies and by invited experts). Developed with the special contribution of the European Association for Cardiovascular Prevention \& Rehabilitation (EACPR). European Journal of Preventive Cardiology 2012;19:585-667.

9. McMurray JJ, Adamopoulos S, Anker SD, Auricchio A, Bohm M, Dickstein K, Falk V, et al. ESC guidelines for the diagnosis and treatment of acute and chronic heart failure 2012: The Task Force for the Diagnosis and Treatment of Acute and Chronic Heart Failure 2012 of the European Society of Cardiology. Developed in collaboration with the Heart Failure Association (HFA) of the ESC. Eur J Heart Fail. 2012;14(8):803-869.

10. Lang RM, Bierig M, Devereux RB, Flachskampf FA, Foster E, Pellikka PA, Picard MH, et al. Recommendations for chamber quantification: a report from the American Society of Echocardiography's Guidelines and Standards Committee and the Chamber Quantification Writing Group, developed in conjunction with the European Association of Echocardiography, a branch of the
European Society of Cardiology. J Am Soc Echocardiogr. 2005;18(12):1440-1463.

11. Cantor WJ, Fitchett D, Borgundvaag B, Ducas J, Heffernan M, Cohen EA, Morrison LJ, et al. Routine early angioplasty after fibrinolysis for acute myocardial infarction. N Engl J Med. 2009;360(26):2705-2718.

12. Scheller B, Hennen B, Hammer B, Walle J, Hofer C, Hilpert V, Winter $\mathrm{H}$, et al. Beneficial effects of immediate stenting after thrombolysis in acute myocardial infarction. J Am Coll Cardiol. 2003;42(4):634-641.

13. Bohmer E, Hoffmann P, Abdelnoor M, Arnesen H, Halvorsen S. Efficacy and safety of immediate angioplasty versus ischemia-guided management after thrombolysis in acute myocardial infarction in areas with very long transfer distances results of the NORDISTEMI (NORwegian study on DIstrict treatment of ST-elevation myocardial infarction). J Am Coll Cardiol. 2010;55(2):102-110.

14. Fernandez-Aviles F, Alonso JJ, Castro-Beiras A, Vazquez N, Blanco J, Alonso-Briales J, Lopez-Mesa J, et al. Routine invasive strategy within 24 hours of thrombolysis versus ischaemia-guided conservative approach for acute myocardial infarction with ST-segment elevation (GRACIA-1): a randomised controlled trial. Lancet. 2004;364(9439):1045-1053.

15. Armstrong PW, Committee WS. A comparison of pharmacologic therapy with/without timely coronary intervention vs. primary percutaneous intervention early after ST-elevation myocardial infarction: the WEST (Which Early ST-elevation myocardial infarction Therapy) study. Eur Heart J. 2006;27(13):1530-1538.

16. Estevez-Loureiro R, Lopez-Sainz A, Perez de Prado A, Cuellas C, Calvino Santos R, Alonso-Orcajo N, Salgado Fernandez J, et al. Timely reperfusion for ST-segment elevation myocardial infarction: Effect of direct transfer to primary angioplasty on time delays and clinical outcomes. World J Cardiol. 2014;6(6):424-433. 